\title{
Ries (Hrsg.)
}

Praxis- und Formularbuch zum Registerrecht 


\section{RWS-Formularbuch}




\title{
Praxis- und Formularbuch zum Registerrecht
}

\author{
3. Auflage \\ 2015 \\ Herausgegeben von \\ RiAG Prof. Dr. Peter Ries, Berlin \\ Bearbeitet von \\ Dipl.-Rpfl. Rita Bauer, Prof. Dr. Peter Ries, Dipl.-Rpfl. Sven Rudolph, \\ Dr. Dr. Christian Schulte M.A.
}

\section{RWW}

RWS Verlag Kommunikationsforum GmbH · Köln 


\section{Zusätzlicher Service im Internet}

Die Vertragsmuster sind unter der Internetadresse http://www.rws-verlag.de/BR-Registerrecht für Sie abrufbar.

Die Deutsche Nationalbibliothek verzeichnet diese Publikation in der Deutschen Nationalbibliografie; detaillierte bibliografische Daten sind im Internet über http://dnb.d-nb.de abrufbar.

(C) 2015 RWS Verlag Kommunikationsforum GmbH

Postfach 2701 25, 50508 Köln

E-Mail: info@rws-verlag.de, Internet: http://www.rws-verlag.de

Alle Rechte vorbehalten. Ohne ausdrückliche Genehmigung des Verlages ist es auch nicht gestattet, das Werk oder Teile daraus in irgendeiner Form (durch Fotokopie, Mikrofilm oder ein anderes Verfahren) zu vervielfältigen.

Satz und Datenverarbeitung: SEUME Publishing Services GmbH, Erfurt Druck und Verarbeitung: CPI books GmbH, Leck 